Niniejsza publikacja jest dostęna na licencji Creative Commons. Uznanie autorstwa-Użycie niekomercyjne-Bez utworów zależnych 3.0 Polska. Pewne prawa zastrzeżone na rzecz autora. Zezwala się na wykorzystanie publikacji zgodnie z licencja - pod warunkiem zachowania niniejszej informacji licencyjnej oraz wskazania autora jako właściciela praw do tekstu. Treść licencji jest dostępna na stronie: http://creativecommons.org/licenses/by-nc-nd/3.0/pl/

Lingwistyka Stosowana 19: 4/2016, 217-228

\author{
Katarzyna TRYCZYŃSKA
}

Uniwersytet Wrocławski

\title{
Problem asymetrii kulturowej w niderlandzkich i angielskich przekładach wybranych polskich powieści współczesnych
}

\begin{abstract}
:
Cultural asymmetry as a problem in the translation of Polish modern literary texts into Dutch and English

Resting on the position of languages and cultures in the world system one may assume that there are different attitudes towards the way in which CSIs are translated into Dutch and English (J. Heilbron 2008 \& 2009). It may appear that more exoticizing procedures are applied by Dutch translators than one may expect to encounter in the English translations. This study shall thus address the issue of the cultural asymmetry and the influence of it on the translation procedures applied to culture-specific elements in the English-language translations of the Polish literary texts dating back to the second half of the $20^{\text {th }}$ century. The corpus of this study consists of Dukla and House of day, house of night and their Dutch and English translations.
\end{abstract}

\section{Wstęp}

Kultura przejawia się częstokroć na wielu płaszczyznach tekstów powstałych w systemie literackim danego kraju, które funkcjonują w określonym kontekście społeczno-kulturowym. Nośnikami kultury są niejednokrotnie elementy kulturowe. Uwidacznia się ona w nich w szczególny sposób, gdyż to one zakotwiczają teksty w konkretnej kulturze i z tego powodu stanowią źródło problemów przekładowych. Kulturę i literaturę należy rozpatrywać w ramach systemu relacji interkulturowych, w którym niemal zawsze występuje pewna asymetria kulturowa. Asymetria ta oddziałuje na proces przekładu i jej wpływ widoczny jest w wybieranych strategiach translatorskich.

Niniejszy artykuł będzie próbą zbadania zależności między asymetrią kulturową a sposobem, w jaki powstają przekłady. Szczególna uwaga zostanie zatem poświęcona wpływowi wyborów translatorskich, dokonywanych w odniesieniu do przekładu elementów kulturowych na ostateczny kształt przekładu, a z drugiej strony refleksji zostanie poddany problem oddziaływania istniejącej asymetrii kulturowej na proces thumaczenia. Dokonam tego na podstawie omówienia wybranych decyzji translatorskich tłumaczy polskiej literatury współczesnej na język niderlandzki i 
angielski. Analizie poddane zostaną przekłady Doти dziennego, doти nосnego O. Tokarczuk i Dukli A. Stasiuka.

Punkt wyjścia dla rozważań stanowią badania przeprowadzone przeze mnie w ramach dysertacji doktorskiej, która była poświęcona analizie elementów kulturowych $\mathrm{w}$ niderlandzkich przekładach polskich powieści współczesnych, stanowiąc jednocześnie studium nad tendencjami przekładoznawczymi w trzech wyodrębnionych okresach (K. Tryczyńska 2014). W celu zgłębienia zarysowanego powyżej problemu, zreferowane badania zostały poszerzone o analizę wyborów translatorskich w odniesieniu do elementów kulturowych oraz zjawiska asymetrii kulturowej $\mathrm{w}$ angielskich przekładach wybranych powieści.

\section{Problem asymetrii kulturowej a przekład}

Dla poniższych rozważań szczególnego znaczenia nabiera konstatacja J. F. Aixelá, wedle której asymetria kulturowa znajduje swoje odzwierciedlenie w dialogu między przedstawicielami odmiennych kultur (J. F. Aixelá 1996: 54). Należy przy tym pamiętać, że dialog ten zachodzi między innymi dzięki przekładowi, który stanowi most między kulturami (zob. O. Carbonell 1996: 93), a thumacz jest postrzegany w tym dialogu jako „animator dialogu pomiędzy różnymi kulturami” (E. Tabakowska 2000: 231). Nie bez znaczenia jest fakt, iż przekład warunkuje w dużym stopniu relacja dominacji i podległości, którą może on podtrzymać bądź zachwiać (zob. L. Venuti 1998: 58).

T. Naaijkens, jeden z czołowych holenderskich teoretyków przekładu, twierdzi, iż „każda kultura nieustannie przesuwa swoje granice względem innych kultur” (T. Naaijkens 2004: 16). Natomiast hegemonia kulturowa przejawia się nie tylko w przekładzie, lecz jest także widoczna w produkcji książek, cyrkulacji literatury, tendencjach literackich (zob. O. Carbonell 1996: 85). Z tego też względu podejście do przekładu literackiego jest odmienne w zależności od badanej kultury, innymi słowy od systemu, w którym przekłady funkcjonują. Istotna jest przy tym pozycja i znaczenie przekładu w obrębie danej kultury oraz jego wpływ na literaturę narodową. I. Even-Zohar zakłada w swojej teorii polisystemu, że przekłady mogą uzyskać prymarne miejsce $\mathrm{w}$ tak zwanych słabych systemach literackich. $Z$ kolei $\mathrm{w}$ systemach literackich określanych mianem silnych rzecz ma się zgoła inaczej i zjawisko to można zaobserwować jedynie, gdy przechodzą one kryzys (I. Even-Zohar 1990: 47).

Spoglądając na problem asymetrii kulturowej z perspektywy socjologicznej, warto przytoczyć stanowisko J. Heilbrona postrzegającego przekład, a w szczególności przekład literacki, jako system międzynarodowy. Transfer kulturowy, jaki zapewnia, a przynajmniej w założeniu powinien gwarantować przekład, rozpatrywany jest $\mathrm{w}$ ramach światowego systemu przekładów, który ma strukturę hierarchiczną (zob. J. Heilbron 2009: 110-111). W rozważaniach J. Heilbrona kluczowa jest pozycja języka, literatury i kultury w obrębie systemu, co stanowi punkt styczny jego założeń teoretycznych z teorią polisystemu I. Even-Zohara. J. Heilbron stosuje nieco odmienną nomenklaturę, rozróżniając języki centralne i peryferyjne. Pozycja języków, tj. ich centralne lub peryferyjne położenie w ramach systemu, wpływa na 
znaczenie tłumaczeń w określonych grupach językowych. Ponadto implikuje ona między innymi, że komunikacja w obrębie języków peryferyjnych odbywa się poprzez i za sprawą języka centralnego. Odnosi się to także do przekładu.

J. Heilbron zalicza język niderlandzki do grupy języków peryferyjnych (2009: 117, 2010: 4), podczas gdy język polski postrzega jako język półperyferyjny (2009: 113). Taki stan rzeczy ma daleko idące konsekwencje dla procesu przekładowego, gdyż w przypadku języków peryferyjnych i półperyferyjnych wyróżnia się następującą tendencję: decyzje dotyczące powstania i wyboru przekładów konkretnych tekstów literackich zależą przeważnie od istnienia przekładu $\mathrm{z}$ danego języka (pół)peryferyjnego na jeden z języków centralnych, który funkcjonuje jako swego rodzaju pośrednik. $\mathrm{W}$ ten sposób naśladowane są wybory centrów międzynarodowych i wyselekcjonowuje się książki zaimportowane już do jednego z języków centralnych (J. Heilbron 2009: 115). W praktyce oznacza to, że przekłady danego tekstu literackiego na język angielski lub niemiecki powstają wcześniej niż przekład na język niderlandzki.

$\mathrm{Z}$ punktu widzenia wyborów translatorskich istotna jest jeszcze jedna konsekwencja takiego stanu rzeczy. Hierarchiczna struktura systemu powoduje mianowicie, że w językach centralnych, gdzie przekłady nie są nad wyraz popularne, pozycja tłumacza nie jest na ogół zbyt wysoka, normy przekładowe zostają zazwyczaj dostosowane do wzorców narodowych, a 'obce' znika w przekładzie. Odwrotnie rzecz się ma w przypadku języków peryferyjnych, gdzie tłumaczenia odgrywają istotną rolę i cieszą się uznaniem, tak jak thumacze, którzy posiadają zazwyczaj szczególny status. W związku z tym egzotyzujące techniki przekładowe są najczęściej stosowane i najbardziej akceptowalne (J. Heilbron 2010: 6) ${ }^{1}$.

W oparciu o powyższe rozważania dotyczące pozycji języków i kultur w światowym systemie można założyć, iż mogą zachodzić rozbieżności w sposobie tłumaczenia elementów kulturowych na język niderlandzki i angielski (zob. J. Heilbron 2008 \& 2009). Dopuszczalne jest wysnucie hipotezy, iż egzotyzujące techniki translatorskie są stosowane częściej przez holenderskich tłumaczy niż ma to miejsce w przypadku tłumaczeń na język angielski. Podstawą, by tak przypuszczać, są konstatacje takich teoretyków jak M. Tymoczko (1999), która twierdzi, iż wiele elementów kulturowych jest niewidocznych w angielskich przekładach. Podobne spostrzeżenia ma L. Venuti (1995), który uważa, iż udomowienie jest w tym zakresie standardową strategią translatorską.

\section{Przekład a tożsamość kulturowa}

Przytoczona powyżej metafora tłumaczenia jako mostu między kulturami jest silnie powiązana $\mathrm{z}$ problemem tożsamości narodowej. Tożsamość jest pojęciem antagonistycznym, ponieważ już w samym pytaniu o tożsamość można upatrywać świadomości różnicy (zob. A. Pstyga 2012: 235). Nie jest ona jednorodną i spójną całością,

\footnotetext{
${ }^{1}$ Podobnie zapatruje się na ten problem także szereg innych teoretyków przekładu: S. Bassnett \& A. Lefevere (1998), P. Casanova (2009), M. Tymoczko (1999) czy też R. Jacquemond (1992).
} 
a wprost przeciwnie jest sfragmentaryzowana i podlega nieustannym transformacjom, co rodzi pewne trudności w ustaleniu, m.in. stopnia, w jakim jest ona powiązana z danym językiem czy też miejscem. Przekład literacki stanowi jeden z czynników wprawiający w ruch procesy transformacyjne, a większość komponentów, jakie składają się na tożsamość kulturową, uwidacznia się dopiero, gdy zostanie uaktywniona $\mathrm{w}$ określonych warunkach. Tak się dzieje na skutek przekładu, zatem wnikliwa analiza tłumaczeń może wzbogacić wiedzę na temat tożsamości kulturowej (zob. J. Heilbron/ G. Sapiro 2007: 103; J. House/ M.R.M. Ruano/ N. Baumgarten 2005: 2). Rola przekładu literackiego w zakresie tworzenia i krystalizowania się tożsamości kulturowej jest nader istotna przede wszystkim w kulturach zdominowanych (por. J. Heilbron/ G. Sapiro 2007: 104).

Przekład wywiera nie tylko zauważalny wpływ na daną kulturę, może on również przyczynić się w pewnym stopniu poprzez interakcję i komunikację, jaką inicjuje, do konstruowania, podtrzymywania bądź modyfikowania tożsamości. Tożsamość kulturowa funkcjonuje także dzięki przekładowi, który jest jednocześnie jej odzwierciedleniem. Tłumacz zostaje osadzony w pewnej „kulturowej strukturze”, co powoduje, że wyraża na swój sposób własną, indywidualną tożsamość oraz wartości, podejmując decyzje translatorskie, tworzy charakterystyczny dla siebie styl przekładowy (zob. T. Ayoma/ J. Wakabayashi 2010: 104).

W przekładzie literackim przebrzmiewa niejednokrotnie głos „obcego”, thumacz zaznajamia bowiem czytelników należących do danej kultury z rozmaitymi przejawami innej kultury bądź innych kultur. C. Robyns (2004: 197) stwierdza, że przekład literacki jako taki jest potrzebny w budowaniu własnej tożsamości kulturowej, jednak może on jednocześnie stanowić dla niej potencjalne zagrożenie, ponieważ za pośrednictwem przekładu wprowadzane są na grunt danej kultury obce elementy, które często odstają od panujących tam norm i konwencji lub nie odpowiadają $\mathrm{w}$ pełni tymże konwencjom. Według C. Robynsa teksty obcojęzyczne i ich przekłady mogą stać się narzędziem w walce o zdefiniowanie własnej tożsamości kulturowej. $\mathrm{Z}$ tego powodu należy w obrębie danej wspólnoty kulturowej przyjąć określone stanowisko względem tłumaczeń, by w ten sposób móc rozwijać, definiować własną tożsamość lub bronić jej, jeśli zajdzie taka konieczność (zob. C. Robyns 2004: 198). W świetle transferu interkulturowego proces negocjacji, kształtowania i obrony tożsamości jest połączony i zależny także od pozycji danej kultury w światowym systemie (zob. K. H. Ryou 2005: 96 e.v.).

„Zetknięcie się różnych języków, obrazów świata oraz tożsamości poprzez przekład nie jest zatem i nie może być łatwe, ponieważ szczególny rodzaj kompetencji (między)-kulturowej odbiorcy decyduje o jakości odbioru i zrozumieniu" (A. Pstyga 2012: 238). W obliczu tego thumacze muszą pełnić w tym procesie rolę uważnych obserwatorów, a także pośredników i mediatorów między kulturami oraz w świadomy sposób decydować o tym, co chcą przekazać i z czym i w jakim stopniu chcą się podzielić z czytelnikami. Oznacza to, iż thumacz musi ogniskować swoją uwagę między innymi na przekonaniach wyrażonych $\mathrm{w}$ tekście wyjściowym wprost lub $\mathrm{w}$ sposób niebezpośredni, a także poddać pod rozwagę sposób, w jaki chce przefiltrować je dla potencjalnych odbiorców przekładu. Na poziomie tożsamości istnieją 
rozmaite czynniki, które odgrywają rolę zarówno w obrębie tekstu, jak i poza nim, stanowiąc ucieleśnienie przekonań oraz wartości, a jednocześnie powodują, że pewne strategie translatorskie stają się w określonych warunkach bardziej lub mniej uprzywilejowane (zob. D. Katan 2009: 90-91). Decyzje podejmowane w odniesieniu do przekładu elementów oryginału odnoszących się w wyraźny sposób do kultury wyjściowej znajdują swoje odzwierciedlenie w określonych technikach translatorskich.

\section{Culture specific items ${ }^{2}$ i wybory translatorskie}

Każdy, kto podejmuje się thumaczenia, zaciąga dług. Aby go spłacić, musi oddać nie te same banknoty czy monety, lecz tę samą kwotę (C.B. West 1932: 344).

Mimo upływu czasu powyższe stwierdzenie nie zdewaluowało się i nadal oddaje problem złożoności decyzji translatorskich. Ich staranny dobór sprawia, że przekazują sensy oryginału czytelnikom, którzy stykają się z tekstami praktycznie z definicji nasyconymi w jakimś stopniu obcością. Teksty te zawierają ,,pewne cechy i jednostki odznaczające się szczególną właściwością: mają one mianowicie zdolność wprowadzania do tekstu sensów, wywołujących u odbiorcy - przez swą niezwykłość, niezgodność z jego doświadczeniem - skojarzenia z obcymi krajami, kulturami i językami”. Powyższa konstatacja R. Lewickiego (1993: 23) odnosi się do cechy tekstów nasyconych odwołaniami kulturowymi, którą badacz określa mianem konotacji obcości.

W ramach przeprowadzonej analizy skupiłam się jedynie na takich elementach wybranych powieści, które w określonym kontekście wykazywały wyraźny związek z kulturą wyjściową. Wyekscerpowałam je i wyselekcjonowałam w oparciu o definicję J. F. Aixelá używającego w odniesieniu do elementów kulturowych określenia culture-specific items (CSIs) (J.F. Aixelá 1996: 58). Koncepcja J.F. Aixeli ma w moim przekonaniu kilka niekwestionowanych zalet, które są w dużej mierze związane z jej dynamicznym charakterem. Po pierwsze nie istnieją stałe elementy kulturowe ani w wymiarze czasowym, ani przestrzennym. Oznacza to, że sposób postrzegania przekładów zmienia się wraz z upływem czasu, a także jest uzależniony od miejsca ich funkcjonowania. Po wtóre elementy kulturowe należy zawsze analizować w kontekście, ponieważ nie istnieją w oderwaniu od niego. Problemy przekładowe, jakie wywołują, są wynikiem ich braku bądź innego statusu intertekstualnego w kulturze docelowej. Po trzecie elementy kulturowe stwarzają trudności przekładowe dopiero w momencie, gdy zostaną oderwane od kultury, do której przynależą, w celu wyrażenia ich w języku kultury docelowej, gdzie, jak już wspomniano, jako takie nie istnieją bądź mają zgoła inny status i znaczenie.

Choć mogłoby się wydawać, że obecność elementów kulturowych może spowodować, iż tłumacz napotka granice przekładalności, warto powtórzyć za E. Balcerzanem (1998: 71): „tłumaczenie jest pokonywaniem nieprzekładalności”. Decyzje tłumacza przynoszą rozwiązania, które okazują się przemawiać w

${ }^{2}$ Całościowe omówienie problemu przedstawiam w mojej rozprawie doktorskiej (K. Tryczyńska 2014). 
większym lub mniejszym stopniu do czytelników przekładu i w założeniu powinny wynikać z obranej strategii translatorskiej. Nie ulega wątpliwości, że nie można oczekiwać identycznego odbioru i doświadczenia od czytelników przekładu, co od czytelników oryginału. Wiąże się to $\mathrm{z}$ przybliżonym charakterem naszej komunikacji, w której pewna niedookreśloność nie wyklucza tego, by przebiegała ona pomyślnie (zob. K. Hejwowski 2004: 73). Istotniejsze wydaje się być i wręcz niezbędne jest uwzględnienie warunków, w jakich dany przekład ma funkcjonować w języku docelowym. To właśnie pozwala tłumaczowi na interpretację sensu bądź sensów tekstu wyjściowego i wybór takich środków, które owe sensy przekażą w przekładzie w sposób zrozumiały dla czytelników pomimo pewnych luk doświadczeniowych (zob. U. Dąmbska-Prokop 2000: 196; I. Panasiuk 2003: 101).

Przekład elementów kulturowych okazuje się być jednym z najbardziej wymagających zadań stawianych tłumaczowi. Tłumacz musi odgrywać różne role w procesie przekładu, a najważniejszym jego zadaniem jest zapewnienie transferu kulturowego (A. Somló 2010: 122). Właściwy dobór technik translatorskich nie jest jednak gwarantem ostatecznego sukcesu. Istotny jest też mianowicie szereg procesów, które decydują o tym, że przekład jest odbierany we właściwy sposób w kulturze docelowej. Ma to spore znaczenie z uwagi na fakt, iż przekład wywiera wpływ na kulturę docelową, współtworząc obraz kultury wyjściowej, do której przynależy oryginał, w tym przypadku kultury polskiej. Kluczowy jest nie tylko tekst jako ciąg znaków. Istotną rolę odgrywają czynniki decydujące o ostatecznym kształcie przekładu i jego cyrkulacji w kulturze docelowej. Mowa tu o takich czynnikach jak decyzja dotycząca thumaczenia danego tekstu i forma, w jakiej przekład zostanie wydany czy też obecność bądź brak posłowia tłumacza.

\section{Analiza}

Z uwagi na szeroki kontekst kulturowy analiza przekładów powinna obejmować cały szereg procesów wymienionych powyżej, które prowadzą do powstania tłumaczenia i zapewniają mu możliwość funkcjonowania w kulturze docelowej. W poniższych rozważaniach chciałabym skupić się jedynie na wycinku takiej analizy, a mianowicie na zbadaniu technik translatorskich zastosowanych w odniesieniu do elementów kulturowych w niderlandzkich i angielskich przekładach Dukli i Domu dziennego, domu nocnego ${ }^{3}$. Analiza wyborów translatorskich jest poszukiwaniem odpowiedzi na pytanie o to, czy przekłady polskiej prozy współczesnej na język angielski i niderlandzki wpisują się w dyskurs, w którym przejawia się asymetria kulturowa. Należy także wspomnieć, iż ze względu na swój ograniczony zasięg badanie to może być postrzegane jako badanie sygnałowe, a analiza i wnioski przedstawione poniżej mogą stanowić punkt wyjścia dla dalszych rozważań.

\footnotetext{
${ }^{3}$ Poniższa analiza została przeprowadzona w oparciu o zmodyfikowany i uzupełniony przeze mnie model zaproponowany przez P. Kwiecińskiego (2001), a w opisie zastosowanych technik tłumaczeniowych posługuję się zaproponowanymi przez badacza anglojęzycznymi określeniami oraz stosuję rozróżnienie pomiędzy strategiami i technikami translatorskimi (zob. K. Tryczyńska 2010).
} 
Analiza procentowego rozkładu wszystkich technik translatorskich w niderlandzkich przekładach dowodzi, iż można mówić w tym przypadku o pewnej równowadze. W obydwu przekładach Karola Lesmana da się zaobserwować inklinację do stosowania technik pośrednich, takich jak borrowing + gloss, wprowadzających do tekstu elementy kulturowe wraz z różnego rodzaju objaśnieniami. W przekładzie Domu dziennego, domu nocnego techniki te pojawiają się w $23 \%$ wszystkich przypadków, natomiast w przekładzie Dukli w nieznacznie mniejszej liczbie, bowiem są obecne w 20\%. Co ciekawe elementy kulturowe obecne w Dukli zostały przetłumaczone na język niderlandzki przy wykorzystaniu technik egzotyzujących w ponad połowie przypadków (53\%). Takie same wybory translatorskie są w wyraźny sposób obecne również w przekładzie Domu dziennego, domu nocnego (31\%).

Najbardziej dominującymi technikami translatorskimi zastosowanymi w niderlandzkim przekładzie Dukli są borrowing (26\%), borrowing + gloss $(20 \%)$ i calque (19\%). Taka konstelacja technik translatorskich sugeruje znaczącą egzotyzację przekładu, jednak ostatecznie nie dzieje się tak na poziomie makrostrukturalnym. $\mathrm{Na}$ poziomie mikrostrukturalnym zauważamy, że Radio Maryja pojawia się w przekładzie w praktycznie niezmienionej formie: Radio Maria, co jest możliwe dzięki podobieństwu leksykalnemu, a typowe marki polskich samochodów ciężarowych zostają jedynie nieznacznie dostosowane pod względem morfologicznym: żuki - Żuks, jelcze - Jelczen, tatra - Tatra's. To samo dzieje się z petetekiem, który pojawia się w przekładzie w postaci skrótu PTTK i zostaje opatrzony komentarzem, podobnie jak Pogórze, pączek czy sołtys. Trzecia wymieniona technika translatorska uwidacznia się w przypadku takich elementów kulturowych jak chociażby utwory muzyczne: Żółty jesienny liść - Het gele herfstblad, a w tym także piosenki z nurtu disco polo, w przypadku których trudno mówić o roli kulturotwórczej, służą jednak autorowi do wykreowania w oryginale specyficznej atmosfery: Siedem dziewcząt z Albatrosa - De zeven meisjes van de Albatros. Co ciekawe technika ta pojawia się w przekładzie także w kombinacji z zapożyczeniem: milicyjna syrenka - een Syrena van de militie. Połączenie tych dwóch egzotyzujących technik translatorskich skutkuje dość niezrozumiałą kombinacją wyrazową mylnie kojarzoną przez czytelników przekładu z policją.

W niderlandzkim przekładzie Domu dziennego, domu nocnego dominują dwie techniki: borrowing (23\%) oraz covert cultural substitution (25\%). Możemy oprócz tego zauważyć, że tłumacz dążył do zachowania równowagi w doborze technik translatorskich i optował za umiarkowanymi rozwiązaniami. I tak oto zauważamy, że borrowing czy też reprodukcja bez objaśnień, korzystając z terminu zaproponowanego przez K. Hejwowskiego (2004: 76), pojawia się w przypadku rozmaitych elementów polskiej rzeczywistości jak: Basztowa - Basztowa, Teleexpress - Teleexpress czy też WARS - WARS. Nie tylko ciekawe, a wręcz zastanawiające jest to, iż mamy do czynienia $\mathrm{z}$ tą techniką translatorską także $\mathrm{w}$ przypadku formy adresatywnej, która jest dla czytelników przekładu całkowicie niezrozumiała: pani magister Pani magister. Znaczna część elementów kulturowych jest tłumaczona przy pomocy całkowicie odmiennej techniki translatorskiej, która powoduje, iż praktycznie stają się one niewidoczne w przekładzie: krupnik - gortsoep, kompot-compote, oscypek 
- rookkaas, tabletki z krzyżykiem - aspirintjes. Warto w tym miejscu zwrócić uwagę na jeden z wymienionych przykładów, chodzi mianowicie o kompot. Na pierwszy rzut oka wydawać by się mogło, że mamy do czynienia z zachowaniem elementu obecnego w oryginale, ponieważ nazwa użyta w przekładzie do złudzenia przypomina polską, jednak w efekcie napój zostaje zastąpiony istniejącym w kulturze docelowej - deserem.

Wyniki analizy angielskich przekładów wskazują na dominację asymilujących technik translatorskich, co sugeruje, iż thumacze uznają ich częste stosowanie za właściwe i uzasadnione. W angielskim przekładzie Dukli techniki udamawiające pojawiają się w $42 \%$ wszystkich analizowanych CSIs, natomiast w Domu dziennym, domu nocnym stanowią one $70 \%$ wszystkich analizowanych elementów kulturowych. W obydwu przekładach covert cultural substitution i normalisation są najczęściej stosowanymi technikami translatorskimi. Wydaje się zatem dość jasne, iż zarówno Bill Johnston, jak i Antonia Lloyd-Jones przy wyborze strategii translatorskiej pochylali się ku udomowienia tekstu.

Analiza wszystkich technik translatorskich zastosowanych przez Billa Johnstona w angielskim przekładzie Dukli dowodzi, że dwoma najbardziej dominującymi są normalisation (28\%) oraz podobnie jak w niderlandzkim przekładzie - borrowing $(22 \%)$. Przekład ten charakteryzuje się podobnymi proporcjami w zastosowaniu poszczególnych technik translatorskich. Jako egzemplifikację pierwszej techniki translatorskiej warto przytoczyć prototypiczne zdanie pojawiające się w polskich elementarzach „To dom, to pies, a to kot Oli” - "This is a house. This is a dog. This is James cat" zastąpione podobnym, neutralnym zdaniem. Innymi przykładami są: milicyjna syrenka - a police car, obywatel - a guy, petetek - the bar at the tourist office, butelki po ptysiu - orangeade bottles czy też słonina - lard. Jeśli zaś chodzi o przykłady zastosowania egzotyzującej techniki - borrowing, do najciekawszych należą Radio Maryja czy Leżajskie. Analogicznie dostrzegamy, że marki samochodów zostają przeniesione w praktycznie niezmienionej formie: żuki - Żuks, jelcze Jelczes, tatra - Tatras. Tak samo dzieje się z góralami - Górals, dukatami - Dukats, wawele-Wawels.

Spoglądając na przekład Domu dziennego, domu nocnego nie można zaprzeczyć, iż zdecydowana większość zastosowanych rozwiązań udomawia tekst. Techniki egzotyzujące są nieliczne, a nawet niezauważalne zważając na to, iż techniki asymilujące: covert cultural substitution (42\%) oraz normalisation (28\%) występują łącznie w ponad 60\% przypadków. Te wybory thumacza Domu dziennego, domu nocnego są zatem znacznie bardziej spolaryzowane niż w przypadku pozostałych tekstów. Antonia Lloyd-Jones zastosowała covert cultural substitution w odniesieniu do: bary mleczne - self-service cafes, kompot - stewed fruit, pierogi - meatballs, placki ziemniaczane - chips, a Polsat stał się satellite TV. Jeśli chodzi o drugą technikę asymilującą przekład zauważamy ją w przypadku: bigos - hot stew, czekolada Goplana - a bar of chocolate, metka - sausage, milicja - the police, pedet - a department store oraz remik - cards. Rzuca się przy tym w oczy fakt, iż tłumaczka kilkakrotnie pominęła $\mathrm{w}$ tłumaczeniu pewne fragmenty oryginału, w których pojawiały się elementy kulturowe. 
Powyższe przykłady uwidaczniają wyraźne różnice w wyborach translatorskich zaobserwowanych w holenderskich i angielskich przekładach. Różnice te unaoczniają choćby takie przykłady, jak: zastąpienie w angielskim przekładzie Teleexpresu całkowicie neutralnym hiperonimem television news, podczas gdy w niderlandzkim przekładzie element ten został zachowany w niezmienionej formie. Podobnie rzecz ma się w przypadku tłumaczenia wyrazów pączek czy petetek. Obydwa odnajdujemy w niderlandzkim tłumaczeniu w niezmienionej formie, podczas gdy w przekładzie na język angielski są praktycznie niedostrzegalne, gdyż zostały przełożone jako doughnut i bar at the tourist office. Oprócz różnic dostrzegamy także pewne podobieństwa i można stwierdzić, że istnieje pewna korelacja przy zastosowaniu przytoczonych powyżej technik egzotyzujacych w przekładzie Dukli, choć ich natężenie w angielskim tłumaczeniu jest znacznie mniejsze. Przykładów jest wiele, niemniej możemy dojść do ciekawych i nieco odmiennych wniosków, gdy przeanalizujemy wybrane elementy kulturowe w szerszym kontekście. Wówczas nasuwa się następujące spostrzeżenie: nie wszystkie z wymienionych elementów kulturowych są w przekładzie w pełni zrozumiałe, choć kontekst pomaga w tym zakresie w dużym stopniu i minimalizuje w znacznym stopniu potencjalną obcość. Przejawem starań tłumacza mających na celu uczynienie przekładu zrozumiałym dla czytelników, którzy określone elementy kultury wyjściowej postrzegają jako obce, wydaje się być zauważalna skłonność do opatrywania egzotycznych elementów przekładu przypisami czy też różnego rodzaju objaśnieniami.

Kolejna obserwacja płynąca z przeprowadzonej analizy brzmi, że dość rzadkie stosowanie technik asymilujących przekład w niderlandzkich tłumaczeniach na korzyść technik egzotyzujących sugeruje, że Karol Lesman wpisał się w zauważalną tendencję będącą wynikiem normy przekładowej panującej w kulturze docelowej. Zamierzenie to zostało w pełni osiągnięte, gdyż czytelnicy niderlandzkich przekładów napotykają elementy naznaczone polskością. Biorąc jednak pod uwagę szeroko pojęty kontekst, ogólna strategia translatorska powinna zostać raczej określona jako umiarkowanie udamawiająca. Pokazuje to, jak znaczący jest kontekst, w którym nawet obcobrzmiące wyrażenia mogą być odbierane jako zrozumiałe, a ich obcość staje się czasem wręcz niedostrzegalna.

Nieco inaczej rzecz się ma na pierwszy rzut oka w przypadku angielskich przekładów Dukli i Domu dziennego, domu nocnego, tam bowiem techniki asymilujące dominują. Warto uzupełnić powyższą konstatację o uwagę dotyczącą przekładu Dukli. Efekt wyborów translatorskich Billa Johnsona świadczyć może o tym, że autor dążył do uzyskania harmonijnego przekładu poprzez zrównoważony dobór technik translatorskich. Spoglądając na obydwa przekłady na język angielski z perspektywy makrostrukturalnej, można stwierdzić, że pole obcości jest w nich wyraźnie zminimalizowane nie tylko poprzez zastosowanie asymilujących technik przekładowych, ale także poprzez kontekst, w jakim elementy kulturowe się pojawiają.

\section{Uwagi końcowe}

Przeprowadzona analiza wskazuje na znaczenie szeroko pojętego kontekstu dla rozpatrywania wyborów translatorskich. Oznacza to zatem, że elementy kulturowe na- 
leży badać zawsze w kontekście kultury, na której grunt zostają przeniesione, a wpływ, jaki na nią wywierają, zależy w dużej mierze od sposobu, w jaki zostają wyrażone, oraz od wspomnianego już kontekstu, w którym funkcjonują. Ponadto świadomość czytelników dotycząca tego, iż mają do czynienia z przekładem, sprawia, że spodziewają się elementów obcej kultury, a wręcz oczekują pewnej inności. Mimo iż obcość kulturowa stanowi dla tłumacza niejednokrotnie spore wyzwanie, wzbogaca kulturę docelową, na grunt której thumacz zaszczepia nowe koncepcje czy terminy.

Zaobserwowana dyskrepancja między niderlandzkimi i angielskimi przekładami analizowanych tekstów w zakresie zastosowanych technik translatorskich może wydawać się na pierwszy rzut oka dość znacząca z uwagi na rozbieżności w przypadku przekładu poszczególnych elementów kulturowych. Należy jednak zauważyć, że różnice między przekładami nie są ostatecznie tak duże, ponieważ na poziomie makrostrukturalnym strategie translatorskie w poszczególnych przekładach możemy postrzegać jako udamawiające.

W związku z powyższym należy pamiętać, iż zmiany lub ich brak w odniesieniu do obecnej sytuacji społeczno-kulturowej i geopolitycznej w kulturze docelowej określają i wpływają na pozycję danego języka i literatury. Są to czynniki, które tłumacz musi brać pod uwagę w pierwszej kolejności przy wyborze strategii translatorskiej, a następnie określonych technik translatorskich w celu stworzenia tekstu odpowiadającego obecnej sytuacji panującej w kulturze docelowej. Dotyczy to także wiedzy czytelników przekładu na temat kultury wyjściowej, jak również norm przekładowych obowiązujących w kulturze docelowej.

Wyniki analizy stanowią wstępne potwierdzenie hipotezy stanowiącej, iż stosunkowo słaba pozycja polskiej kultury względem kultury anglo-amerykańskiej znajduje swoje odzwierciedlenie w przekładzie na język angielski w postaci dominacji technik udomawiających. Z kolei peryferyjna pozycja holenderskiej kultury $i$ języka niderlandzkiego $\mathrm{w}$ połączeniu ze skłonnością holenderskich tłumaczy do stosowania egzotyzujących technik translatorskich potwierdza założenie, że tak zwany import kulturowy odgrywa istotną rolę w Niderlandach. Zatem tendencja do stosowania egzotyzujących rozwiązań w niderlandzkich przekładach i jej brak w angielskich przekładach stanowi potwierdzenie tezy M. Tymoczko (1999). W przekonaniu badaczki w językach i kulturach peryferyjnych przekład jest wszechobecny i ma spore znaczenie dla między innymi rozwoju literatury. Status thumaczy jest w takich kulturach wysoki, a wybory translatorskie ogniskują się przeważnie wokół technik egzotyzujących. Natomiast w obrębie kultur i języków dominujących jest odwrotnie. Świadczy to także o tym, że asymetria kulturowa między dwoma wspólnotami językowymi i kulturowymi znajduje swoje odzwierciedlenie w dyskursie członków tychże wspólnot i można podsumować to słowami O. Carbonella (1996: 85), który twierdzi, iż hegemonia kulturowa zawsze znajduje swoje odzwierciedlenie w przekładzie. 


\section{Bibliografia}

Aixelá, J. F. (1996), Culture-specific Items in Translation, (w:) R. Alvarez/ M.C.A. Vidal (red.), Translation, Power, Subversion. Clevedon/ Philadelphia/ Adelaide, $52-78$.

Ayoma, T./ J. Wakabayashi (2010), Identity and Relationships in Translated Japanese Literature, (w:) C. Maier/ F. Massardier-Kenney (red.), Literature in Translation. Teaching Issues and Reading Practices. Kent/ Ohio, 101-116.

Balcerzan, E. (1998), Czym jest nieprzekładalność - faktem praktyki translatorskiej czy zmyśleniem teoretyków?, (w:) P. Fast (red.), Przekład artystyczny a współczesne teorie translatologiczne. Katowice, 57-71.

Bassnett, S./ A. Lefevere (1998), Constructing Cultures. Essays on Literary Translation. Clevedon etc.

Carbonell, O. (1996), The Exotic Space of Cultural Translation, (w:) R. Alvarez/ M.C. A. Vidal (red.), Translation, Power, Subversion. Clevedon/ Philadelphia/ Adelaide, 79-98.

Casanova, P. (2002, 2009), Consecration and accumulation of literary capital. Translation as unequal exchange, (w:) M. Baker (red.), Translation studies. Critical Concepts in Linguistics, vol. II, 85-107.

Dąmbska-Prokop, U. (2000), Mała encyklopedia przekładoznawstwa. Częstochowa.

Even-Zohar, I. (1978, 1990), The Position of Translated Literature within the Literary Polysystem, (w:) Polysystem Studies, Poetics Today, 11 (1), 45-51.

Hejwowski, K. (2004), Kognitywno-komunikacyjna teoria przektadu. Warszawa.

Heilbron, J./ G. Sapiro (2007), Outline for a sociology of translation. Current issues and future prospects, (w:) M. Wolf/ A. Fukari (red.), Constructing a Sociology of Translation Studies, 93-107.

Heilbron, J. (1999, 2009), Towards a sociology of translation. Book translations as a cultural world- system, (w:) M. Baker (red.), Translation studies. Critical Concepts in Linguistics, vol. II, 108-124.

Heilbron, J. (2010), Structure and Dynamics of the World System of Translation, (http://portal.unesco.org/culture/es/files/40619/12684038723Heilbron.pdf/Heilbr on.pdf; pobrano 08.04.2016).

House, J./ M. R. M. Ruano/ N. Baumgarten (2005), Introduction, (w:) J. House/ M.R. M. Ruano/ N. Baumgarten (red.), Translation and the Construction of Identity. IATIS Yearbook 2005. Seoul, 1-12.

Jacquemond, R. (1992), Translation and Cultural Hegemony: The Case of FrenchArabic Translation, (w:) L. Venuti (red.), Rethinking Translation - Discourse, Subjectivity, Ideology. London/ New York, 139-58.

Katan, D. (2009), Translation as intercultural communication, (w:) J. Munday (red.), The Routlegde Companion to Translation Studies. London - New York, 74-92.

Kwieciński, K. (2001), Disturbing strangeness. Toruń.

Lewicki, R. (1993), Konotacja obcości w przekładzie. Lublin. 
Naaijkens, T. (2004), Een wereld van verschil. Over taal en cultuur in vertaling, (w:) S. Evenepoel/ G. Rooryck/ H. Verstraete (red.), Taal en cultuur in vertaling. De wereld van Cees Noteboom. Antwerpen/ Apeldoorn, 13-23.

Panasiuk, I. (2003), Miejsce modelu lakun w obrębie teorii tlumaczenia kultur, (w:) K. Hejwowski (red.), Teoria i dydaktyka przekładu. Olecko, 99-112.

Pstyga, A. (2012), Przekład jako spotkanie różnych tożsamości, (w:) Slavia Meridionalis, 12, 235-247.

Robyns, C. (2004), Eigen vertoog eerst. Vertaling als een bedreiging voor cultureleIdentiteit, (w:) A. B. M. Naaijkens/ H. Bloemen/ C. Koster/ C. Meijer (red.), Denken over vertalen. Tekstboek Vertaalwetenschap. Nijmegen, 197208.

Ryou, K. H. (2005), Aiming at the Target. Problems od Assimilation and Identity in Literary Translation, (w:) J. House/ M. R. M. Ruano/ N. Baumgarten red.), Translation and the Construction of Identity. IATIS Yearbook 2005. Seoul, 96108.

Sánchez, M. T. (2009), The Problems of Literary Translation: A Study of the Theory and Practice of Translation from English into Spanish. Bern.

Somló, A. (2010), The Role of Literary Translators in the Mediation of Ideas and Literature Across Culture, (w:) T. Naaijkens (red.), Event of incident. On the Role of Translation in the Dynamics of Cultural Exchange. Bern etc., 121-140.

Tabakowska, E. (2000), Poprawność polityczna jako kryterium oceny przekładu, (w:) O. Kubińska/ W. Kubiński (red.), Przekładając nieprzekładalne III. Gdańsk, 217-232.

Tryczyńska, K. (2010), Over de transfer van Poolse cultuurgebonden elementen bij de vertaling. Enkele theoretische overwegingen, (w:) Neerlandica Wratislaviensia, XIX, 159-175.

Tryczyńska, K. (2014), Vertaaltendensen in de Nederlandse vertalingen van Poolse hedendaagse romans. Een vergelijkende studie van cultuurgebonden elementen, niepublikowana dysertacja doktorska, Uniwersytet Wrocławski, 2014.

Tymoczko, M. (1999), Post-colonial writing and literary translation, (w:) S. Bassnett/ H. Trivedi (red.), Post-colonial Translation. London/ New York, 19-41.

Vandeweghe, W. (2005), Duo teksten. Inleiding tot vertaling en vertaalstudie. Gent.

Venuti, L. (1998), The Scandals of Translation: Towards an Ethics of Difference. London.

West, C. B. (1932), La théorie de la traduction au XVIII siècle, (w:) Revue Littérature Comparée, 12, 330-355. 